\title{
La difusión en internet de los museos de arte contemporáneos españoles
}

\author{
Vicent Giménez Chornet \\ Universidad Politécnica de Valencia
}

Se analizan los sitios web de los museos de arte contemporáneo españoles para identificar cuáles son las Tecnologías de la Información y la Comunicación que han implementado. Tras proponer quince tecnologías que se consideran apropiadas para la difusión de los museos y la comunicación con los usuarios, describiendo individualmente sus características e interés para los museos, se analiza su grado de uso en los sitios web. Se concluye que las redes sociales más usadas son Facebook y Twitter, y para la difusión de los audiovisuales se utilizan las redes de YouTube y Vimeo, pero que también empiezan a irrumpir tecnologías más recientes como Foursquare o alguna app para teléfono celular. Con el uso de estas y otras tecnologías descritas el museo consigue difundir sus contenidos y generar interés a los usuarios.

\section{TIC, Difusión en internet; Museos de Arte Contemporáneo; Redes sociales, Catálogos en} línea; Facebook, Twitter; Flickr, Youtube, Comunicación

Websites of the Spanish contemporary art museums are analyzed to identify the Information Technology and Communication is implemented. After fifteen propose technologies that are considered appropriate for museums and dissemination of communication with users, describing their characteristics individually and interest for museums, their level of use is analyzed websites. It is concluded that social networks are Facebook and Twitter most used, and for the dissemination of audiovisual network YouTube and Vimeo are used, but also begin to break more recent technologies such as Foursquare or some cell phone app. With the use of these and other technologies described the museum gets spread their content and generate interest to users.

\section{ICT, Internet Broadcasting; Museum of Contemporary Art; Social Networking, Online catalogs; Facebook, Twitter; Flickr, Youtube, Communication}

\section{Introducción}

Mediante la aplicación de las Tecnologías de la Información y la Comunicación en los museos se está logrando un acercamiento de las colecciones museísticas al ciudadano, democratizando su conocimiento y posibilitando que esta institución cultural desempeñe también funciones educativas. No es que la práctica de la difusión de los contenidos de los museos sea nueva o reciente, pues ya desde del siglo XVII se daban las reuniones de "gabinete de curiosidades" donde unos "eruditos" buscaban entretener, sorprender o divertir a una reducida audiencia, pero manteniendo una relación estrecha con el objeto museístico'. La diferencia en la actualidad es que el ciudadano puede tener una relación virtual con el objeto, cumpliendo el objetivo museístico de contemplación e incluso de educación e investigación. También se ha destacado cómo la difusión de las colecciones museográficas virtuales pueden beneficiar el turismo de la población donde radica el museo².

1 Zana Brigitte, 2005. History of the museums, the mediators and scientific education, Journal of Science Communication, 4 (4), December 2005, pp- 1-6.

2 Carreras César, Berni, Piero 2003. Difusió del patrimoni cultural a través de les TIC: el cas del portal de la vall de Boí, Digithum [en línea]. UOC. Núm. 5. [Consulta:8/05/2014] Disponible en: http://www.uoc.edu/humfil/ articles/cat/carreras0303/carreras0303.html. 
Internet está en continua evolución y se prevé que en los próximos años la gestión de datos desde diferentes dispositivos devendrá en el Internet de las Cosas, en un mundo hiperconectado donde la gestión de la información será crucial para procesar e interpretar esos datos. En este contexto, la evolución de la información museística necesita ser gestionada para un nuevo entorno de usuarios, dado que éstos la consultan cada vez más en internet desde diferentes dispositivos: tablets, smarphones, readers, ordenadores portátiles, etc.; es en definitiva, una información creada para la difusión, que puede ser complementaria de la información producida en el museo como consecuencia de las investigaciones o análisis propios de la misión establecida.

En el presente artículo pretendemos analizar los canales utilizados para la difusión de los museos de arte contemporáneo españoles, mediante la identificación de dichos canales en internet y su grado de uso en los museos.

\section{Los museos}

Los últimos datos publicados sobre estadística de los museos y colecciones museográficas españoles indican, según la ratio por visitantes de museo abierto, que los museos de arte contemporáneo son los más visitados. Aunque en valores absolutos hay más visitas en los museos de bellas artes, esto se debe en parte a que hay un mayor número de estos museos. Sin embargo las estadísticas demuestran que las visitas a los museos de arte moderno y contemporáneo son las más abundantes en España.

El resultado de la estadística publicada por el Ministerio de Educación, Cultura y Deporte muestra, según las áreas de conocimiento, el grado de interés de los visitantes. Como podemos apreciar en los datos y en el gráfico, los museos más visitados son los de Arte Contemporáneo, seguidos por los de Ciencia y Tecnología, Bellas Artes, de Sitio (sitios monumentales) y de Historia.

\begin{tabular}{|c|c|c|c|c|}
\hline Tipología & $\begin{array}{l}\text { № de mu- } \\
\text { seos }\end{array}$ & $\begin{array}{c}\text { Total visitan- } \\
\text { tes }\end{array}$ & $\begin{array}{l}\text { Visitantes } \\
\text { por museo }\end{array}$ & $\begin{array}{l}\text { Visitantes por } \\
\text { museo abierto }\end{array}$ \\
\hline Arte Contemporáneo & 126 & 11.830 .577 & 93.893 & 99.417 \\
\hline Ciencia y Tecnología & 56 & 4.833 .691 & 86.316 & 86.316 \\
\hline Bellas Artes & 227 & 15.762 .784 & 69.440 & 71.649 \\
\hline Otros & 5 & 256.870 & 51.374 & 64.218 \\
\hline De Sitio & 37 & 1.897 .627 & 51.287 & 54.218 \\
\hline Historia & 111 & 5.010 .239 & 45.137 & 45.137 \\
\hline General & 144 & 5.213 .964 & 36.208 & 37.243 \\
\hline Arqueológico & 173 & 4.924 .493 & 28.465 & 29.488 \\
\hline Artes Decorativas & 33 & 919.986 & 27.878 & 27.878 \\
\hline Especializado & 140 & 3.033 .303 & 21.666 & 21.822 \\
\hline Casa-Museo & 92 & 1.958 .256 & 21.285 & 21.519 \\
\hline Ciencias Naturales e Historia Natural & 58 & 1.164 .158 & 20.072 & 20.424 \\
\hline Etnografía y Antropología & 262 & 2.214 .752 & 8.453 & 8.895 \\
\hline
\end{tabular}




\section{Visitantes por museo abierto según tipología, año 2012}

\begin{tabular}{|c|c|}
\hline Arte Contemporáneo & Ciencia y Tecnología \\
\hline GBellas Artes & Dotros \\
\hline GDe Sitio & QHistoria \\
\hline घGeneral & arqueológico \\
\hline घArtes Decorativas & QEspecializado \\
\hline GCasa-Museo & $\square$ Ciencias Naturales e \\
\hline
\end{tabular}

MEtnografía y Antropología

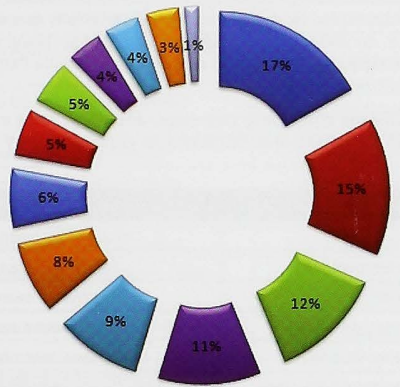

De entre los museos de arte contemporáneo destacamos el Museo Nacional Centro de Arte Reina Sofia (http://www.museoreinasofia.es/). Es uno de los museos de arte contemporáneo más visitados del mundo, a pesar de su juventud, pues fue inaugurado en 1992. Su extraordinaria colección, sede del conocido mural Guernica de Pablo Picasso, más sus actividades (participación en proyectos nacionales e internacionales, docencia en másteres y cursos, participación en congresos, etc. ${ }^{3}$ ) permiten su difusión paralelamente a su sitio web.

El MACBA (Museu d'Art Contemporani de Barcelona) es otro de los museos creados recientemente, inaugurado en 1995, gracias al impulso de la Generalitat de Catalunya y el Ayuntamiento de Barcelona que promovieron la constitución de la Fundación Museu d'Art Contemporani de Barcelona unos años antes, en 1985. La Fundación MACBA aglutina a personas particulares y a empresas (actualmente con ochenta particulares y sesenta empresas) ${ }^{4}$. Contiene una importante colección con obras representativas de Miquel Barceló, Eduardo Chillida, Joan Miró, Antoni Tàpies, Andy Warhol, y muchos otros, reuniendo obras no sólo de catalanes o españoles, sino también de artistas latinoamericanos u otros artistas internacionales. Recientemente han incorporado obras de artistas del norte de África y de países árabes.

3 Museo Reina Sofía. Memoria de actividades 2011 [en línea]. Disponible en: http://www.museoreinasofia.es/sites/ default/files/memoria/2011/memoria-completa-2011.pdf.

4 MACBA. Museu d'Art Contemporani de Barcelona [en línea]. Disponible en: http:/www.macba.cat/es/historia 
EI MUSAC (Museo de Arte Contemporáneo de Castilla y León) es uno de los museos de arte contemporáneo más recientes, inaugurado en 2005, en León. Es un museo público creado por la comunidad autónoma de Castilla y León, y gestionado por la Junta de Castilla y León. Sus fondos originarios son los del mismo gobierno autonómico, incrementándose a partir del establecimiento del Comité de Adquisiciones que ha permitido la incorporación de obras de artistas nacionales e internacionales, alcanzando en la actualidad 1.650 obras de unos 400 artistas $^{5}$.

El IVAM (Instituto Valenciano de Arte Moderno), junto con el MUVIM (Museu Valencià de la Il-lustració i la Modernitat), son los museos más representativos del arte contemporáneo en la ciudad de Valencia; los dos son de carácter público. El IVAM fue inaugurado en 1989 con la misión de fomentar el arte contemporáneo, y es propiedad de la Generalitat Valenciana, el gobierno autonómico de dicha comunidad ${ }^{6}$, mientras que el MUVIM ha sido creado más recientemente, en 2001, bajo la titularidad de la Diputación de Valencia, para difundir las obras de la modernidad, acogiendo en su edificio la Sala Parpalló con programación de arte contemporáneo?

El total de museos relacionados con el arte contemporáneo españoles en los que hemos analizado la incorporación de las TIC, que favorecen su comunicación y difusión, son los siguientes:

\begin{tabular}{|c|c|}
\hline MUSEO & URL \\
\hline Centre d'Art la Panera & http://www.lapanera.cat \\
\hline Centro Andaluz de Arte Contemporáneo & http://www.caac.es/ \\
\hline Centro Atlántico de Arte Contemporáneo & http://www.caam.net/ \\
\hline Centro de Arte Contemporáneo de Málaga & http://cacmalaga.eu/ \\
\hline Centro de Arte Contemporáneo Huarte & http://www.centrohuarte.es/ \\
\hline Centro de Arte Contemporáneo José Guerrero & http://www.centroguerrero.org/ \\
\hline Centro Galego de Arte Contemporánea & http://www.cgac.org/ \\
\hline Centro-Museo Vasco de Arte Contemporáneo & http://www.artium.org/ \\
\hline Colecciones Artísticas Fundación Mapfre & http://www.coleccionesfundacionmapfre.org/ \\
\hline DA2 Domus Artium 2002 & http://www.domusartium2002.com/ \\
\hline $\begin{array}{l}\text { ESBALUARD Museu d'Art Modern i Contemporani } \\
\text { de Palma }\end{array}$ & http://www.esbaluard.org \\
\hline Fundació Antoni Tàpies & http://www.fundaciotapies.org \\
\hline Fundació Chirivella Soriano & http://www.chirivellasoriano.org/\# \\
\hline Fundació Gala-Salvador Dalí & http://www.salvador-dali.org \\
\hline Fundació ICO & http://www.fundacionico.es \\
\hline Fundació Joan Miró & http://www.fundaciomiro-ben.org/ \\
\hline Fundació Pilar i Joan Miró & http://miro.palmademallorca.es/ \\
\hline Fundación Museo Jorge Oteiza & http://www.museooteiza.org \\
\hline
\end{tabular}

5 MUSAC. Museo de Arte Contemporáneo de Castilla y León len línea|. Disponible en: http://www.musac.es

6 IVAM. Institut Valencià d'Art Modern [en línea]. Disponible en: http:/wwwivam.es/

7 MUVIM. Museu Valencià de la II·lustració i la Modernitat [en línea]. Disponible en: http://www.muvim.es/el muvim.html. 


\begin{tabular}{|c|c|}
\hline $\begin{array}{l}\text { Fundación NMAC Montenmedio Arte Contempo- } \\
\text { ráneo }\end{array}$ & http://www.fundacionnmac.org/ \\
\hline Guggenheim Bilbao & http://www.guggenheim-bilbao.es/ \\
\hline $\begin{array}{l}\text { IAACC Instituto Aragonés de Arte y Cultura Con- } \\
\text { temporánea }\end{array}$ & http://www.iaacc.es/ \\
\hline IVAM Institut Valencià d'Art Modern & http://www.ivam.es/ \\
\hline MACBA Museu d'Art Contemporani de Barcelona & http://www.macba.cat/ \\
\hline MARCO Museo de Arte Contemporáneo de Vigo & http://www.marcovigo.com/ \\
\hline MEAM Museu Europeu d’Art Modern & http://www.meam.es/ \\
\hline $\begin{array}{l}\text { MUSAC Museo de Arte Contemporáneo de Casti- } \\
\text { lla y León }\end{array}$ & http://www.musac.es/ \\
\hline $\begin{array}{l}\text { MUSARCO Museo de Arte Contemporáneo } \\
\text { Aragonés }\end{array}$ & http://www.musarco.com/ \\
\hline Museo Art Nouveau y Art Déco Casa Lis & http://www.museocasalis.org/ \\
\hline Museo de Arte Abstracto Español-Cuenca & http://www.march.es/arte/cuenca/ \\
\hline Museo de Arte Contemporáneo de Alicante & http://www.maca-alicante.es/ \\
\hline Museo de Arte Contemporáneo de Eivissa & http://www.eivissa.es/mace/index.php \\
\hline $\begin{array}{l}\text { Museo de Arte Contemporáneo Español Patio } \\
\text { Herreriano }\end{array}$ & http://www.museopatioherreriano.org/ \\
\hline $\begin{array}{l}\text { Museo de Arte Contemporáneo Gas Natural } \\
\text { Fenosa }\end{array}$ & http://www.mac.gasnaturalfenosa.com \\
\hline $\begin{array}{l}\text { Museo de Arte Moderno y Contemporáneo de } \\
\text { Santander y Cantabria }\end{array}$ & http://www.museosantandermas.es/ \\
\hline $\begin{array}{l}\text { Museo Extremeño e Iberoamericano de Arte } \\
\text { Contemporáneo }\end{array}$ & http://www.meiac.es/ \\
\hline Museo Nacional Centro de Arte Reina Sofía & http://www.museoreinasofia.es/ \\
\hline Museo Picasso Málaga & http://museopicassomalaga.org/ \\
\hline Museo Würth La Rioja & http://www.museowurth.es/ \\
\hline $\begin{array}{l}\text { Museu d'Art Contemporani Vicente Aguilera } \\
\text { Cerni-Vilafamés }\end{array}$ & http://macvac.vilafames.es/ \\
\hline $\begin{array}{l}\text { MUVIM Museu Valencià de la II·lustració i la } \\
\text { Modernitat }\end{array}$ & http://www.muvim.es/ \\
\hline REKALDE & http://www.salarekalde.bizkaia.net/ \\
\hline Sala Parpalló & http://www.salaparpallo.es/ \\
\hline TEA - Tenerife Espacio de las Artes & http://www.teatenerife.es/ \\
\hline
\end{tabular}

Muchos de estos museos han nacido recientemente debido a que cada comunidad autónoma ha impulsado su creación. Entre sus objetivos ha prevalecido la promoción del arte contemporáneo en su colectividad, mediante la incorporación de obras de artistas locales y la organización de actividades que dinamizan la reflexión y disfrute de la obra contemporánea. 
Otro grupo de museos lo constituyen las fundaciones relacionadas con artistas, que recogen las obras que éstos han incorporado a la fundación para su museología. Son, en general, museos relevantes de grandes artistas contemporáneos españoles, como los museos vinculados a las obras de Joan Miró, Antoni Tàpies o Salvador Dalí. El museo dedicado a la obra del destacado artista Pablo Picasso en Málaga es una colección menor, escasa, creada por iniciativa local en reconocimiento del pueblo natal a su pintor predilecto.

\section{Las TIC en los museos}

Para analizar el grado de implementación de las Tecnologías de la Información y Comunicación en los museos hemos seleccionados aquellas que consideramos más sobresalientes, que permiten, de algún modo, que el museo se comunique con sus usuarios en línea y, por tanto, potenciales usuarios presenciales. Algunas aplicaciones informáticas hacen posible que los usuarios puedan consultar y visualizar las obras de los artistas gracias a las bases de datos que ofrece el catálogo en línea, pudiendo disfrutar de la imagen digitalizada de la obra y saber la descripción de la misma con fines de estudio o análisis. Son 15 aplicaciones informáticas que permiten diferentes funcionalidades de comunicación entre los usuarios y la entidad museística, como las redes sociales más populares, por ejemplo Facebook, o los repositorios de imagen o audiovisuales igualmente populares, como Flickr o YouTube, pero también aplicaciones con algunas funcionalidades particulares de comunicación que describimos seguidamente.

Facebook: la red social creada por Mark Zuckerberg en julio de $2004^{8}$. La red social permite, además de ofrecer la información esencial del museo como su dirección, teléfono, horario, etc., comunicar a sus seguidores las actividades inmediatas, de forma más eficaz y ágil que la web corporativa, generalmente más estática. Al mismo tiempo, sus seguidores pueden opinar y compartir dicha información con su propia comunidad.

Twitter: esta aplicación de microblogging fue creada en 2006 en la sede de la compañía Odeo, Inc., y se caracteriza por enviar mensajes con el límite de 140 caracteres $^{9}$. La aplicación ha tenido una gran difusión entre los usuarios de smartphones, permitiendo la consulta de información desde cualquier sitio en cualquier momento. Su uso por los museos permite enviar información de acontecimientos u opiniones de sus actividades a su comunidad de seguidores, mediante frases cortas que favorecen su lectura rápida. Además, a estos tuits (mensajes) se les puede enlazar imágenes o videos de los eventos que se están celebrando en el momento, proporcionando una inmediatez de la información museística no alcanzada por las otras redes sociales, y facilitando que sus seguidores opinen y la compartan con sus propias comunidades.

Flickr: esta red social, repositorio de fotografia, nace en 2004 en la empresa Ludicorp, de Vancouver, y posteriormente es adquirida en 2005 por Yahoo $^{10}$. Flickr facilita a los museos crear dos opciones de divulgar las fotografias de su fondo expositivo. Por una parte, de forma institucional, puede crear una cuenta donde, mediante la publicación de álbumes (colecciones de fotografias por temas), el museo ofrece al público en general las imágenes que la propia entidad ha producido, por ejemplo el Museo Reina Sofía ofrece 200 álbumes de fotos ${ }^{11}$. Por otra parte, si el museo permite la realización de fotografias a sus usuarios,

8 FACEBOOK. Notice of annual meeting of stockholders to be held on may 22, 2014 [en línea]. Disponible en: https:/ materials.proxyvote.com/Approved/30303M/20140324/NPS_200750/\#/1/

9140 CHARACTERS. How Twitter was born [en línea], 30 de enero de 2009. Disponible en: http:// www.140characters.com/2009/01/30/how-twitter-was-born/, entre cuyos empleados se encontraban @jack, @Biz,@Noah,@Crystal, @Jeremy, @Adam, @TonyStubblebine, @Ev, @Dom, @Rabble, @RayReadyRay, @Florian,@TimRoberts, y@Blaine.

10 SANKAR, Krishna; BOUCHARD, Susan A. Enterprise Web 2.0 fundamentals. Indianapolis: Cisco Press, 2009 , p. 60.

11 FLICKR. Museo Reina Sofia. Álbumes [en línea]. Disponible en: https:/www.flickr.com/photos/museoreinasofia/ sets/ 
poder ofrecer por esta red social las fotografias de sus visitantes que considera más interesantes, haciendo partícipes a los mismos usuarios de la difusión del museo o de sus actividades; esta opción también la ejerce el Museo Reina Sofía ${ }^{12}$.

YouTube y Vimeo: son dos redes sociales con una misma finalidad, difundir los audiovisuales que sus usuarios suben a su repositorio. YouTube fue creada en 2005 por Chad Hurley, Steve Chen, y Jawed Karim, y en 2006 fue adquirida por Google ${ }^{13}$. Frente al uso inicial de personas particulares subiendo videos, las empresas han visto también el potencial de realizar campañas de marketing por este medio ${ }^{14}$. Vimeo fue creada un año antes, en 2004, en New York, por un grupo de cineastas que apostaban por una buena calidad del audiovisual ${ }^{15}$. Estas dos redes sociales permiten que las entidades museísticas suban sus videos, haciendo posible que sus usuarios opinen o compartan dicha información. Si bien Vimeo apuesta por una calidad de imagen, YouTube ofrece la posibilidad de transformar la voz en subtítulos, y su traducción automatizada a diversos idiomas, para facilitar la comunicación en este mundo globalizado.

Instagram: es una red social para compartir fotografias en el teléfono móvil, creada en 2010 por Kevin Systrom y Mike Krieger, en San Francisco. La novedad de esta aplicación es que el usuario puede aplicar, desde el mismo teléfono, algunos filtros, con diferentes efectos (como vintage) y marcos, y compartir inmediatamente dicha foto no sólo en el repositorio propio de Instagram, sino también el Facebook, Flickr o Twitter ${ }^{16}$. El museo puede crear una cuenta en Instagram y ofrecer todas aquellas fotos (posts) que el organismo ha creado y difundido desde Instagram por diferentes redes sociales, especialmente Twitter. Los usuarios pueden indicar que les gusta, realizar comentarios o seguir. Un ejemplo lo tenemos en el Centro de Arte Contemporáneo de Málaga ${ }^{17}$.

Foursquare: es una aplicación, creada en 2009, que presta un servicio basado en la geolocalización para permitir a las personas mantenerse en contacto, reunirse y, especialmente, descubrir lugares. La gente puede opinar de las entidades, en nuestro caso de los museos, y hacer recomendaciones. Algunos sitios web de museos insertan el enlace a Foursquare para que el usuario que utiliza un smartphone pueda guardar la información del mismo, por ejemplo el Museo Europeo de Arte Moderno, de Barcelona. Es una aplicación móvil que gestiona una gran cantidad de datos geoespaciales creados durante mucho tiempo por los ciudadanos a través de la adición de los lugares visitados ${ }^{18}$.

RSS: son las siglas de Rich Site Summary, deribado del RDF Site Summary, pero también conocido como Really Simple Syndication, y se trata de una TIC que permite distribuir contenidos de sitios web, generalmente en XML para garantizar la compatibilidad con diferentes sistemas de ordenadores, y que contienen textos cortos con algunos metadatos, como su fecha de publicación o el nombre del autor. Sirve fundamentalmente para recibir novedades de la web mediante un lector RSS o un agregador de noticias ${ }^{19}$.

12 FLICKR. Museo Reina Sofia. Favoritas [en línea]. Disponible en: https:/www.flickr.com/photos/museoreinasofia/ favorites/

13 Hopkins, Jim. Surprise! There's a third YouTube co-founder [en línea], USA Today. 2009. Disponible en: http:/ usatoday30.usatoday.com/tech/news/2006-10-11-youtube-karim_x.htm

14 Miller, Michael. YouTube for business: online video marketing for any business. Indianapolis, Ind.: Que, 2010.

15 VIMEO. Acerca de Vimeo [en línea]. Disponible en: http://vimeo.com/about

16 Una pequeña guía de uso en Joseph LINASCHKE, Getting the Most from Instagram [en línea]. Peachpit Press (Google eBook), 2011.

17 INSTAGRAM. Cac Málaga len línea]. Disponible en: http://instagram.com/cacmalaga

18 Edoh-Alove, Elodie; Hubert, Frédéric; Badard, Thierry. A Web Service for Managing Spatial Context Dedicated to Serious Games on and for Smartphones, Journal of Geographic Information System, 2013, 5, 148-160. http:// dx.doi.org/10.4236/jgis.2013.52015

19 Fissore, María L; Gustavo Rodríguez, Alfredo Gómez; Tanburi, Dario Oscar. Web 2.0: Wikis RRS. Córdoba: Eduvim, 2010, pp. 53-55. 
Pinterest: esta red social fue lanzada en 2010, y su finalidad es compartir imágenes en la web, tanto las que el responsable de realizar un tablero (como se denomina el espacio donde se agrupan las imágenes) pueda encontrar en cualquier sitio web como las que pueda subir de su propia colección. Los museos pueden crear tableros de imágenes con sus temas o actividades de las que disponen información visual, como por ejemplo el museo de la Fundació Antoni Tàpies de Barcelona (http://www.pinterest.com/ fundaciotapies/)

Delicius: es un marcador social web. Creado en 2003, ha pasado por varios propietarios, especialmente de Yahoo, aunque en 2011 fue vendido a AVOS, y en 2014 a Science Inc ${ }^{20}$. Como marcador social su función es compartir las direcciones URL favoritas con los usuarios que visiten el Delicius creado por un responsable. Un ejemplo de aplicación lo tenemos en Artium (https://delicious.com/Artium_Vitoria)

Google Plus: a veces escrito Google +, es la red social lanzada en 2011 para competir con Facebook. Permite crear círculos de diferentes categorías de gente, o añadir tus categorías (Amigos, Familiares, etc.) para poder difundir la información a la comunidad según interés. Cualquier usuario que visite el Google Plus de un museo lo puede añadir a sus círculos. El museo que dispone de Google Plus ofrece la información de seguidores que tiene y el número de visitas. Un ejemplo lo tenemos en el Centro de Arte Contemporáneo de Málaga.

LinkedIn: es una red social de carácter profesional lanzada en 2003, para facilitar los contactos entre profesionales que pueden consultar un currículo abreviado. Sirve para empleadores o para solicitantes de empleo. Al museo esta red le permite publicar su trayectoria profesional y, especialmente, favorecer la búsqueda de contactos como empleador, y ofrecer noticias para posicionarse en la difusión de la información.

Catálogo online: todos los museos catalogan sus obras, pero ofrecer una imagen de la obra con sus características a los usuarios que consultan la web es más escaso. La finalidad de ofrecer una visualización de las obras, con su descripción, es incrementar la difusión del museo, para su estudio y conocimiento, sin menoscabo de una disminución de visitantes. Al contrario, la visualización de las obras en la web es un motivo de atracción para visitar y visualizar el original ${ }^{21}$.

Publicaciones online: muchos museos publican libros, revistas o pequeñas monografias relacionadas con las exposiciones, sus obras, o trabajos científicos, pero pocas ofrecen su visualización online. Actualmente, poco a poco, algunos museos ofrecen, además del ejemplar impreso para su compra, la adquisición gratuita o por compra de la obra en diferentes formatos (ebook, pdf, visualización en flash, etc.), desde su sitio web o enlazando a algún editor gratuito en línea. Un ejemplo de publicaciones ofrecidas online es el MACBA (http:// www.macba.cat/ca/qp), que se pueden comprar o descargar.

App: nos referimos a aplicaciones para smartphones, especialmente para IOS (de Apple) o Android. Algunos museos generan sus propias apps para ser descargadas en los teléfonos móviles y comunicar a los usuarios información destacada del museo.

Blog: es el sitio web donde se pueden publicar artículos y comunicarse con los usuarios, permitiendo que éstos realicen comentarios. La posibilidad de ofrecer textos, imágenes,

20 Fiegerman, Seth. Bookmarking Site Delicious Acquired for the Third Time in 10 Years (en línea), Mashable (2014). Disponible en: http://mashable.com/2014/05/08/delicious-acquired-science-ind

21 Un ejemplo lo tenemos en la visita al museo del Louvre, la mayor parte de la gente tiene interés por ver el original de La Gioconda, a pesar de haberla visto innumerables veces en la web, incluso con una imagen de buena resolución. 
objetos multimedia o datos ${ }^{22}$ abre las posibilidades a los museos para comunicar información dinámica e interactiva a sus usuarios.

\section{El impacto de las TIC}

El análisis de los sitios web de los museos de arte contemporáneo españoles se ha realizado en la segunda quincena del mes de mayo de 2014. En total se han seleccionado 43 museos o centros de arte contemporáneo con actividad museística. La identificación de las aplicaciones seleccionadas no implica que sean las únicas que utilizan los museos españoles, pero sí son las mayoritarias.

En el siguiente cuadro y gráfico podemos visualizar cuales son las más requeridas por los museos:

\begin{tabular}{|l|c|c|c|}
\hline \multicolumn{4}{|c|}{ TIC USADAS POR LOS MUSEOS DE ARTE CONTEMPORÁNEO } \\
\hline TIC & Número & TIC & Número \\
\hline Facebook & 36 & Blog & 8 \\
\hline Twitter & 33 & Google + & 6 \\
\hline Youtube / Vimeo & 28 & Delicius & 5 \\
\hline Flickr & 19 & Foursquare & 3 \\
\hline RSS & 15 & Linkedln & 3 \\
\hline Catálogo online & 15 & App & 3 \\
\hline Publicaciones online & 12 & Instagram & 1 \\
\hline Pinterest & 8 & & \\
\hline Fuente: elaboración propia & & & \\
\hline
\end{tabular}

La mayor parte de los museos utiliza Facebook, con un total de 36 de ellos. Es la red social más popular en la sociedad y esto se traslada también a su uso en los museos, ya que de esta forma se garantiza que una gran parte de la gente dispondrá de acceso sin muchas complicaciones al Facebook del museo, haciendo posible la comunicación entre entidad y usuario.

La siguiente TIC más usada es Twitter en 33 museos. Igualmente es un reflejo de la importante penetración de esta tecnología en la sociedad actual. La limitación de los 140 caracteres facilita que los usuarios puedan consultar con rapidez todos los tuits que pueda enviar el museo, especialmente en el smartphone, y si es de su interés, retuitearlos a sus seguidores. De esta forma el museo puede conseguir una difusión más rápida y ágil que en Facebook, dado que ésta se presta a redacciones más extensas.

El tercer elemento más usado por los museos para difundir sus actividades es el audiovisual, que lo publican en las redes sociales de YouTube o Vimeo. En 28 museos, más de la mitad de los analizados, utilizan las dos redes o una de ellas para divulgar exposiciones, entrevistas o simplemente dar noticia de visitas, actividades u otros eventos.

Las TIC siguientes ya representan un uso inferior a la mitad de los museos analizados. La aplicación más importante es la red social de fotografía Flickr, implementada en 19

22 Castelló Martínez, Araceli. Estrategias empresariales en la Web 2.0: las redes sociales online. Alicante: Club Universitario, 2010, p. 56. 


\section{USO DE LAS TICS EN LOS MUSEOS}
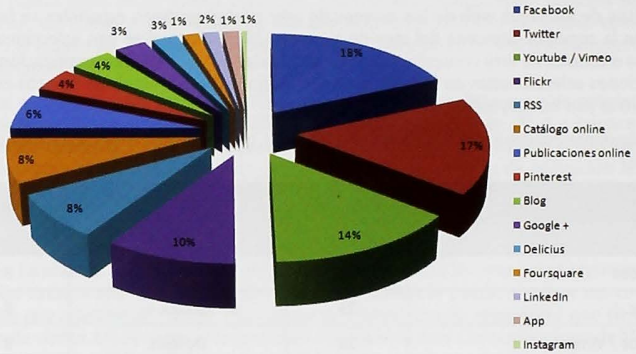

museos. Es la red de estas características más popular, mientas que las otras relacionadas también con la imagen tienen una presencia menor: Pinterest en 8 museos e Instagram solamente en 1 museo.

La posibilidad de ofrecer un catálogo en línea de las obras de los museos, una actividad tan difundida en bibliotecas o en archivos, es aún baja en estas entidades culturales, solamente en 15 museos. Consideramos que uno de los grandes retos de los museos del siglo XXI, en la Sociedad de la Información, es precisamente el volcado de sus catálogos a bases de datos consultables en internet.

La posibilidad de ofrecer publicaciones en abierto $^{23}$, independientemente de las adquisiciones por compra, es otra de las opciones que pueden implementar los museos para difundir el conocimiento de sí mismos por un canal más apropiado. 12 museos han apostado por esta línea, y en algunos casos, si el usuario desea obtener la publicación impresa, es posible previo pago.

El uso de blog, una aplicación bastante difundida en la sociedad, no ha tenido la misma importancia en los museos, que sólo lo han implementado 8 de ellos. El resto de las TIC (Google Plus, Delicius, Foursquare, LinquedIn o las Apps) tienen una presencia más minoritaria. Google Plus no se acerca al impacto detectado en su rival Facebook, a pesar de las prestaciones mejoradas de esta importante empresa. Tampoco Foursquare ha proliferado en los museos, a pesar de que el visitante detectará en su teléfono móvil la presencia del museo, por geolocalización, pero sin información del mismo. En cuanto a la creación de una App propia para el museo, sólo lo llevan a cabo 3 centros. Suponemos que el incremento de los smartphones en la sociedad favorecerá el incremento de apps para museos.

El análisis de la cantidad de TIC que puede llegar a utilizar un museo para conseguir una mayor comunicación en internet es la otra cuestión que nos ha interesado averiguar. En el siguiente gráfico podemos visualizar el número de TIC utilizadas por los museos (ver Anexo para su listado).

23 Siguiendo la iniciativa de acceso abierto al conocimiento tras la declaración de Budapest: http:/www. budapestopenaccessinitiative.org/translations/spanish-translation 
El museo que más TICs utiliza, 12 de la 15 analizadas, no es de los museos con un mayor presupuesto: el Centro de Arte Contemporáneo de Málaga. Han creado un sitio web muy

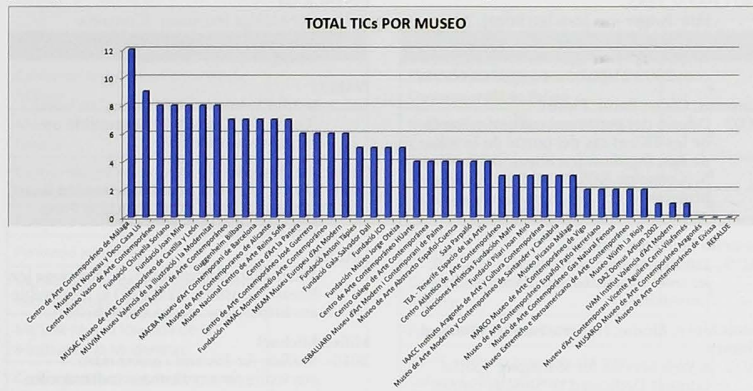

comunicativo para reflejar las actividades que realizan. Los siguientes museos en importancia de TICs implementadas tampoco son los de mayores presupuestos: el Museo Art Nouveau y Art Déco Casa Lis, con 9, y el Centro-Museo Vasco de Arte Contemporáneo, la Fundación Chirivella Soriano de Valencia, la Fundación Joan Miró, el MUSAC y el MUVIM, con 8. Museos más representativos o más visitados, como el Guggenheim de Bilbao, el MACBA de Barcelona o incluso el Museo Reina Sofia utilizan menos de la mitad de las TICs analizadas. El resto de los museos solamente ha implementado unas cuantas TICs, fundamentalmente Facebook y Twitter, habiendo 3 museos que no han aplicado ninguna TIC, manteniendo su sitio en los niveles de la web 1.0.

\section{Conclusión}

El desarrollo de las TIC ha penetrado en los sitio web de los museos españoles de arte contemporáneo con diferente intensidad, no especialmente vinculada a sus presupuestos o a la importancia de visitantes, siendo algunos museos de menos impacto internacional los que más han implementado una mayor diversidad de canales para comunicarse con sus usuarios.

Las redes sociales más difundidas en la sociedad, como Facebook o Twitter, son las que también han sido mayormente implementadas en los museos, junto con la posibilidad de difundir audiovisuales por las redes populares de YouTube y Vimeo. Sin embargo, otras TIC que podrían ser de gran utilidad para comunicar información y atraer visitantes, como ofrecer un catálogo de sus obras en línea o la popular app de geolocalización Foursquare aún son escasamente implementadas.

Los museos españoles sobre arte contemporáneo son los más visitados y tal vez, a falta de una investigación más pertinente, les haya favorecido la difusión de su existencia en internet y el uso de las TIC, ya que muchos de ellos han sido creados en las últimas décadas. Estas TIC pueden ilusionar a los visitantes, haciéndolos partícipes con sus opiniones, y permitiendo el incremento de la difusión de la información museística, ya que los usuarios, con las funcionalidades de la web 2.0 , la pueden compartir con sus propios seguidores. 


\section{Bibliografía}

\section{CHARACTERS}

How Twitter was born [en línea], 30 de enero de 2009. [Consulta: 3/06/2014] Disponible en: http://www.140characters. com/2009/01/30/how-twitter-was-born/

Carreras, César; Berni, Piero

2003 Difusió del patrimoni cultural a través de les TIC: el cas del portal de la vall de Boí, Digithum [en línea]. UOC. Núm. 5. [Consulta: 8/05/2014] Disponible en: http://www.uoc.edu/humfil/articles/cat/ carreras0303/carreras0303.html

Castelló Martínez, Araceli

2010 Estrategias empresariales en la Web 2.0: las redes sociales online. Alicante: Club Universitario

Edoh-Alove, Elodie; Hubert, Frédéric; Badard, Thierry

2013 A Web Service for Managing Spatial Context Dedicated to Serious Games on and for Smartphones, Journal of Geographic Information System, 5, 148-160. http://dx.doi.org/10.4236/ jgis. 2013.52015

\section{FACEBOOK}

Notice of annual meeting of stockholders to be held on may 22, 2014 [en línea). [Consulta: 3/06/2014]Disponible en: https://materials.proxyvote. com/Approved/30303M/20140324/ NPS_200750/\#/1/

Fiegerman, Seth

2014 Bookmarking Site Delicious Acquired for the Third Time in 10 Years [en línea], Mashable . [Consulta: 6/06/2014] Disponible en: http://mashable.com/2014/05/08/ delicious-acquired-science-inc/

Fissore, María L; Gustavo Rodríguez, Alfredo Gómez; Tanburi, Dario Oscar 2010 Web 2.0: Wikis RRS. Córdoba: Eduvim.

\section{FLICKR}

Museo Reina Sofia. Álbumes [en línea]. [Consulta: 3/06/2014] Disponible en: https://www.flickr.com/photos/ museoreinasofia/sets/ Museo Reina Sofia. Favoritas [en línea]. [Consulta: 3/06/2014]Disponible en: https:/www.flickr.com/photos/ museoreinasofia/favorites/

Hopkins, Jim

2006 Surprise! There's a third YouTube co-founder [en línea], USA Today. [Consulta: 3/06/2014]. Disponible en: http://usatoday30.usatoday.com/tech/ news/2006-10-11-youtube-karim_x.htm

\section{INSTAGRAM}

Cac Málaga [en línea]. [Consulta: 3/06/2014] Disponible en: http:// instagram.com/cacmalaga

IVAM

Institut Valencià d'Art Modern [en línea]. [Consulta: 22/05/2014]Disponible en: http://www.ivam.es/

Linaschke, Joseph

2011 Getting the Most from Instagram [en línea]. [Consulta: 3/06/2014]. Peachpit Press (Google eBook)

\section{MACBA}

Museu d'Art Contemporani de Barcelona len línea]. [Consulta: 22/05/2014] Disponible en: http://www.macba.cat/es/historia

Miller, Michael

2010 YouTube for business : online video marketing for any business. Indianapolis, Ind.: Que

Ministerio de Educación, Cultura y Deporte

2012 Estadística de Museos y Colecciones museográficas [en línea]. [Consulta: 8/05/2014] Disponible en: http://www. mcu.es/estadisticas/docs/MC/EM/2012/ Estadistica de_Museos y_Colecciones Museograficas_2012.pdf

\section{MUSAC}

Museo de Arte Contemporáneo de Castilla y León [en línea]. [Consulta: 22/05/2014] Disponible en: http://www.musac.es

\section{Museo Reina Sofía}

2012 Memoria de actividades 2011 [en línea]. [Consulta: 15/05/2014] Disponible en: http:/www.museoreinasofia.es/sites/ default/files/memoria/2011/memoriacompleta-2011.pdf

\section{MUVIM}

Museu Valencià de la $I / \bullet$ lustració $i$ la Modernitat (en línea]. [Consulta: 22/05/2014] Disponible en: http://www. muvim.es/el_muvim.html

Sankar, Krishna; Bouchard, Susan A.

2009 Enterprise Web 2.0 fundamentals. Indianapolis: Cisco Press.

\section{VIMEO}

Acerca de Vimeo len línea]. [Consulta: 3/06/2014]Disponible en: http://vimeo. com/about

Zana, Brigitte

2005 History of the museums, the mediators and scientific education, Journal of Science Communication, 4 (4), December 2005, pp. 1-6. 


\section{Anexo}

Listado de museos y TIC utilizadas

\begin{tabular}{|c|c|}
\hline MUSEO & TOTAL TIC \\
\hline $\begin{array}{l}\text { Centro de Arte Contemporáneo de } \\
\text { Málaga }\end{array}$ & 12 \\
\hline $\begin{array}{l}\text { Museo Art Nouveau y Art Déco } \\
\text { Casa Lis }\end{array}$ & 9 \\
\hline $\begin{array}{l}\text { Centro-Museo Vasco de Arte Con- } \\
\text { temporáneo }\end{array}$ & 8 \\
\hline Fundació Chirivella Soriano & 8 \\
\hline Fundació Joan Miró & 8 \\
\hline $\begin{array}{l}\text { MUSAC Museo de Arte Contemporá- } \\
\text { neo de Castilla y León }\end{array}$ & 8 \\
\hline $\begin{array}{l}\text { MUVIM Museu Valencià de la } \\
\text { Il-lustració i la Modernitat }\end{array}$ & 8 \\
\hline $\begin{array}{l}\text { Centro Andaluz de Arte Contempo- } \\
\text { ráneo }\end{array}$ & 7 \\
\hline Guggenheim Bilbao & 7 \\
\hline $\begin{array}{l}\text { MACBA Museu d'Art Contemporani } \\
\text { de Barcelona }\end{array}$ & 7 \\
\hline $\begin{array}{l}\text { Museo de Arte Contemporáneo de } \\
\text { Alicante }\end{array}$ & 7 \\
\hline $\begin{array}{l}\text { Museo Nacional Centro de Arte } \\
\text { Reina Sofía }\end{array}$ & 7 \\
\hline Centre d'Art la Panera & 6 \\
\hline $\begin{array}{l}\text { Centro de Arte Contemporáneo José } \\
\text { Guerrero }\end{array}$ & 6 \\
\hline $\begin{array}{l}\text { Fundación NMAC Montenmedio } \\
\text { Arte Contemporáneo }\end{array}$ & 6 \\
\hline $\begin{array}{l}\text { MEAM Museu Europeu d'Art } \\
\text { Modern }\end{array}$ & 6 \\
\hline Fundació Antoni Tàpies & 5 \\
\hline Fundació Gala-Salvador Dalí & 5 \\
\hline Fundació ICO & 5 \\
\hline Fundación Museo Jorge Oteiza & 5 \\
\hline $\begin{array}{l}\text { Centro de Arte Contemporáneo } \\
\text { Huarte }\end{array}$ & 4 \\
\hline $\begin{array}{l}\text { Centro Galego de Arte Contempo- } \\
\text { ránea }\end{array}$ & 4 \\
\hline
\end{tabular}

\begin{tabular}{|c|c|}
\hline MUSEO & TOTAL TIC \\
\hline $\begin{array}{l}\text { ESBALUARD Museu d'Art Modern i } \\
\text { Contemporani de Palma }\end{array}$ & 4 \\
\hline $\begin{array}{l}\text { Museo de Arte Abstracto Español- } \\
\text { Cuenca }\end{array}$ & 4 \\
\hline Sala Parpalló & 4 \\
\hline TEA - Tenerife Espacio de las Artes & 4 \\
\hline $\begin{array}{l}\text { Centro Atlántico de Arte Contem- } \\
\text { poráneo }\end{array}$ & 3 \\
\hline $\begin{array}{l}\text { Colecciones Artísticas Fundación } \\
\text { Mapfre }\end{array}$ & 3 \\
\hline Fundació Pilar i Joan Miró & 3 \\
\hline $\begin{array}{l}\text { IAACC Instituto Aragonés de Arte y } \\
\text { Cultura Contemporánea }\end{array}$ & 3 \\
\hline $\begin{array}{l}\text { Museo de Arte Moderno y Contem- } \\
\text { poráneo de Santander y Cantabria }\end{array}$ & 3 \\
\hline Museo Picasso Málaga & 3 \\
\hline $\begin{array}{l}\text { MARCO Museo de Arte Contempo- } \\
\text { ráneo de Vigo }\end{array}$ & 2 \\
\hline $\begin{array}{l}\text { Museo de Arte Contemporáneo } \\
\text { Español Patio Herreriano }\end{array}$ & 2 \\
\hline $\begin{array}{l}\text { Museo de Arte Contemporáneo Gas } \\
\text { Natural Fenosa }\end{array}$ & 2 \\
\hline $\begin{array}{l}\text { Museo Extremeño e Iberoamericano } \\
\text { de Arte Contemporáneo }\end{array}$ & 2 \\
\hline Museo Würth La Rioja & 2 \\
\hline DA2 Domus Artium 2002 & 1 \\
\hline IVAM Institut Valencià d'Art Modern & 1 \\
\hline $\begin{array}{l}\text { Museu d'Art Contemporani Vicente } \\
\text { Aguilera Cerni-Vilafamés }\end{array}$ & 1 \\
\hline $\begin{array}{l}\text { MUSARCO Museo de Arte Contem- } \\
\text { poráneo Aragonés }\end{array}$ & 0 \\
\hline $\begin{array}{l}\text { Museo de Arte Contemporáneo de } \\
\text { Eivissa }\end{array}$ & 0 \\
\hline REKALDE & 0 \\
\hline
\end{tabular}




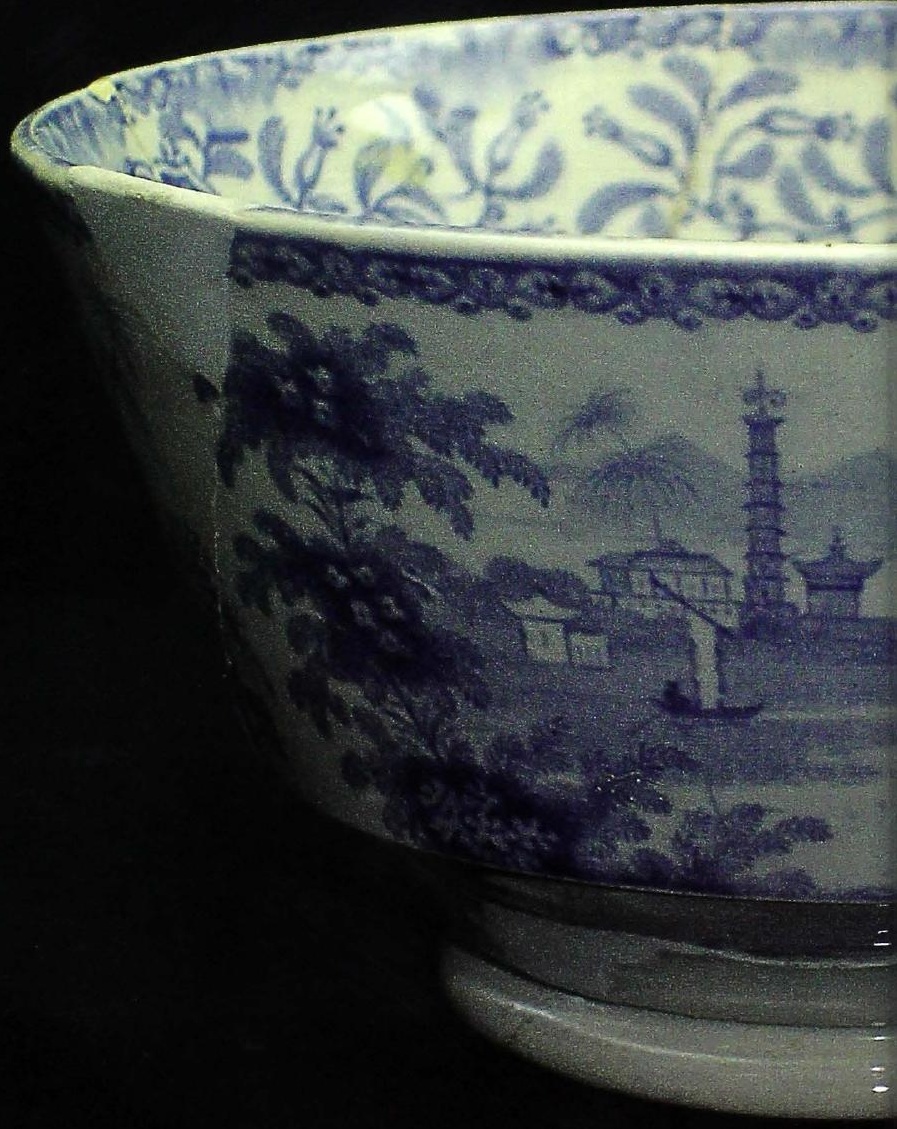

